\title{
Wind energy utilisation for water desalination, street and buildings lighting - a case study for The Emirate of Ajman - UAE
}

\author{
Abdul Salam K. Darwish* \\ University of Bolton, Bolton, United Kingdom
}

Received: 15 February 2021 / Received in final form: 22 March 2021 / Accepted: 23 March 2021

\begin{abstract}
Electricity demand is increasing worldwide due to the advancements in lifestyle, technology, and increased population. Governments are facing common challenges to generate electricity from low-cost and clean energy resources. Water desalination, air-conditioning, and lighting are the main sectors that consume a significant amount of electricity with great demand in the Gulf Cooperation Council (GCC) countries. Many countries' water shortage problem, specifically in the Gulf area, has led to increased challenging electricity demand. Electric power is currently generated from mainly fossil fuel, which has an enormous ongoing impact on environmental pollutions and, thus, climate problems. UAE has recently started to look and was managed to deploy environmental-friendly energy resources, such as renewables for power generation. Attempts were made to utilise solar energy for desalination systems, and none of these attempts was made regarding using wind energy systems. The water need is met by seawater desalination. This purpose's energy consumption is getting high with the increase of demand to separate the salt from seawater. There exists more consumption in building and street lighting. Ajman is the smallest Emirate in the UAE, which imports its power from the neighbouring emirates with a cost to be paid. This research reviews the feasibility of resourcing more than $20 \%$ of the electricity demand by wind energy to satisfy power needs towards desalination and lighting for street and official and newly built buildings. Wind energy potential at the Emirate of Ajman has been reviewed and showed a suitable wind energy potential for utilisation to supply more than $20 \%$ of the demand of about $350 \mathrm{MW}$. A windpowered desalination system can meet the water demand when a properly design system is to be installed.
\end{abstract}

\section{Introduction}

The energy use per capita has increased in recent years as the lifestyle, and everyday items increase worldwide, resulting in an increased demand for energy. Electricity is a significant type of energy demand. It will be a prime sector of power demand for the future as most countries are heading for applications that only operate by electricity. Fossil fuel is to be limited for petrochemical industries. Primary energy demand differs from one country to another. GCC countries are consuming electricity, mainly for Airconditioning, water desalination, building, and lighting purposes see Figure 1, for residential consumption [1].

All this demand is primarily met by fossil fuel. UAE has recently realised that its carbon footprint and overall pollutions are significantly increasing, and the country started to look for alternative energy resources [2]. Figure 2

\footnotetext{
* e-mail:a.darwish@bolton.ac.uk
}

shows the amount of CO2 emission per annum 1990-2050 regarding the historical periods, present situation, and forecast to 2050. The effect of COVID-19 is also demonstrated [3]. Before the COVID-19 pandemic, the UAE's greenhouse gas emissions present $46-58 \%$ increase above 2010 levels and show that the implemented policies are insufficient to stop emissions from increasing beyond 2020. The COVID-19 pandemic's impact on future emissions could decrease the emission by around 10-16\% below our pre-COVID-19 is estimated by 2030 when the Government's recent planned green - sustainable projects and policies are implemented [3].

Seawater desalination is a prime resource that significantly contributes to electricity consumption in the UAE and substantially impacts the environment. The alternative to fossil fuel energy resource of electricity could minimise the impact on the environment, and sustainable which provide affordable, accessible, and reliable energy to satisfy the economic, social and environmental needs [4]. As one of the GCC regions, UAE needs to utilise two sources of energy, solar and wind, as solar can cover the daily demand 


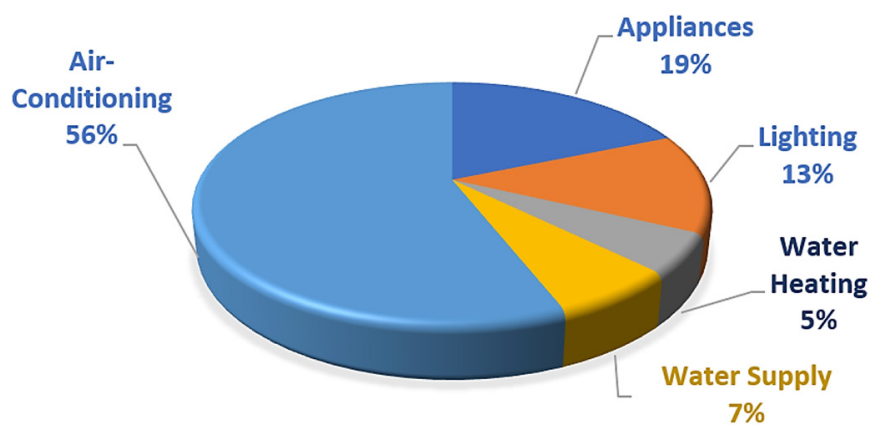

Fig. 1. Residential electricity consumption per person/day GCC [1].

only to a certain extent. Still, wind can substitute the lack of supply in the nighttime. Ajman, the smallest Emirate, could practically utilise these two sources to cover some of the energy needs. Wind energy utilisation depends on several factors. These factors are the available wind speed frequency distribution over several years, social acceptance, economic benefits, technical support, distance from the main electricity grids, and environmental impact. Matching between the site suitability and the suitablewind turbines is an important issue before installing wind turbines in any country. Several studies were done to specify the most relevant sites and showed the feasibility of implementation; for instance, see [5]. Renewable energy is an attractive solution to minimise the effect of desalination plants on the carbon footprint. It also reduces the associated cost eliminating the difference between the water and fuel prices [6]. Technologies for desalination were mainly used globally and practically found that Reverse Osmosis (RO) dominates the industry and recommends its implementation [7-9]. RO is the desalination process with the lowest energy requirements, and coastal areas present a high availability of wind power resources. According to some authors, wind-powered RO plants appear to be one of the most promising renewable energy desalination [10-12]. Many wind data research outcomes recommended wind energy utilisation in the UAE.

For example, in areas around the west of UAE, Saleous et al. [13] have concluded that some offshore areas are unsuitable due to restricted zones (marine protected areas, oil extraction platforms, and oil pipelines in particular). However, some suitable offshore sites could be identified, especially around Delma Island and North of Jabal Barakah in the Western Region [13]. Onshore suitability is available for many areas. Street Lighting is another application for utilising wind energy, specifically at motorways, as there is plenty of wind created by vehicle motion. A suitable system for the Emirate of Ajman consists of hybrid resource (Solar \& Wind) will save a considerable amount of electricity and enhance Sustainable Emirate's efforts.

Moreover, wind turbine technology is suitable and feasible to light the buildings and save a minimum of $10 \%$ of the buildings' electricity demand. This can be achieved by integrating wind technology or hybrid systems (Solar/ Wind) with the newly built buildings. It will have the advantage to have the buildings moving towards sustainable buildings and be environmentally friendly.

\section{Wind energy potential in Ajman - UAE}

\subsection{Wind resource assessment}

Wind resources must be assessed carefully. It is a prime contributor to wind energy potential analysis. It directly affects decision-making in designing and selecting the wind farms and the suitable wind turbines to extract the maximum available wind energy for a chosen area. Figure 3 [14] summarises the assessment process.

\subsection{Wind energy potential in UAE}

Data presented by the UAE wind atlas $[15,16]$ shows that the country is experiencing mean average wind speeds between 5.5 and 7.5 at $100 \mathrm{~m}$ height ( buildings average heights) for most of the year. Wind speed in the UAE is generally below $10 \mathrm{~m} / \mathrm{s}$ for most of the year. Figure 4 extracted from [16] indicates areas with potential wind farms (offshore) onshore). Maximum wind speeds are more likely to be in the southern inland areas, which have higher wind speeds. However, coastal areas are with promising wind potential.

\subsection{Wind energy potential in Ajman}

Two areas were selected for the Emirate of Ajman coastal and on land. The average wind speed at the coastal area shows wind speeds at different heights shown in Figure 5. data adapted from [15]. Monthly mean wind speeds are in the range of $6.5-7.5 \mathrm{~m} / \mathrm{s}$ are most likely at heights higher than $50 \mathrm{~m}$. Figure 6, data adapted from [15], shows the monthly mean wind speeds on land areas which shows 6.0-7.0 m/s are most likely at the buildings' height. To model thewind's vertical profile of the wind, the extrapolation of the speed $\mathrm{v}\left(\mathrm{z}_{10}\right)$ measured on a level $\mathrm{z}_{10}$ towards a level $\mathrm{z}_{2}$ is written by the law ofpower by the expression $[17,18]$ :

$$
v\left(z_{2}\right)=v\left(z_{10}\right)\left(\frac{z_{2}}{z_{10}}\right)^{\alpha 1}
$$

where, $v\left(z_{2}\right)=$ wind speed at the hub height $z_{2}, v\left(z_{10}\right)=$ wind speed at the original height $\mathrm{z}_{10}, \alpha_{1}=$ surface roughness coefficient, it is determined from the following expression [19]

$$
\alpha_{1}=\frac{\left[0.37-0.088 \ln \left(v_{10}\right)\right]}{\left[1-0.88 \ln \left(\frac{z_{10}}{10}\right)\right]}
$$

\subsection{Wind powered desalination system}

The operating systems and strategies proposed for water desalination are numerous and highly diverse. Three designs are available for the wind-powered desalination system [14]:

- The integration of desalination technologies and wind energy generation systems in the corresponding conventional power distribution grids;

- The use of stand-alone micro-grids where the desalination plants are connected directly to the wind energy generation systems; 


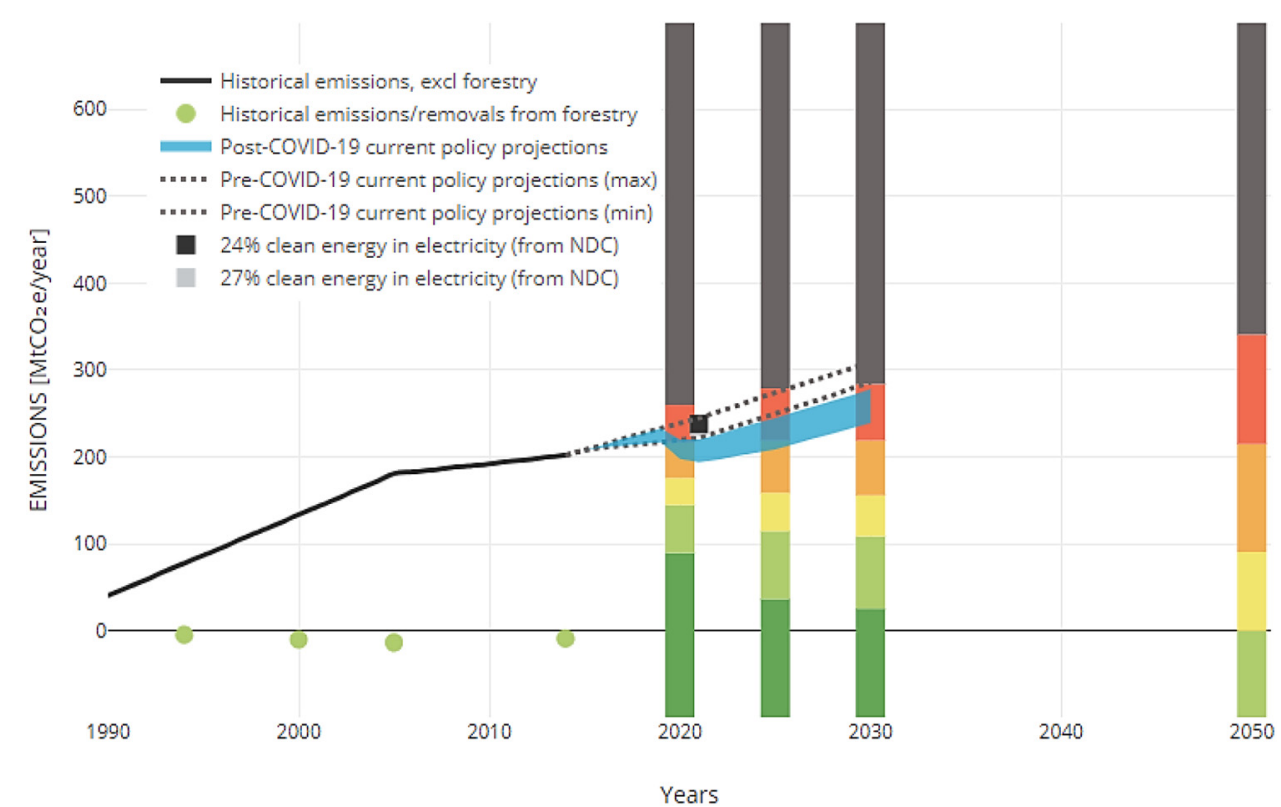

Fig. 2. Historical, post COVID-19, pre COVID-19 and forecasted carbon emissions in UAE [3].

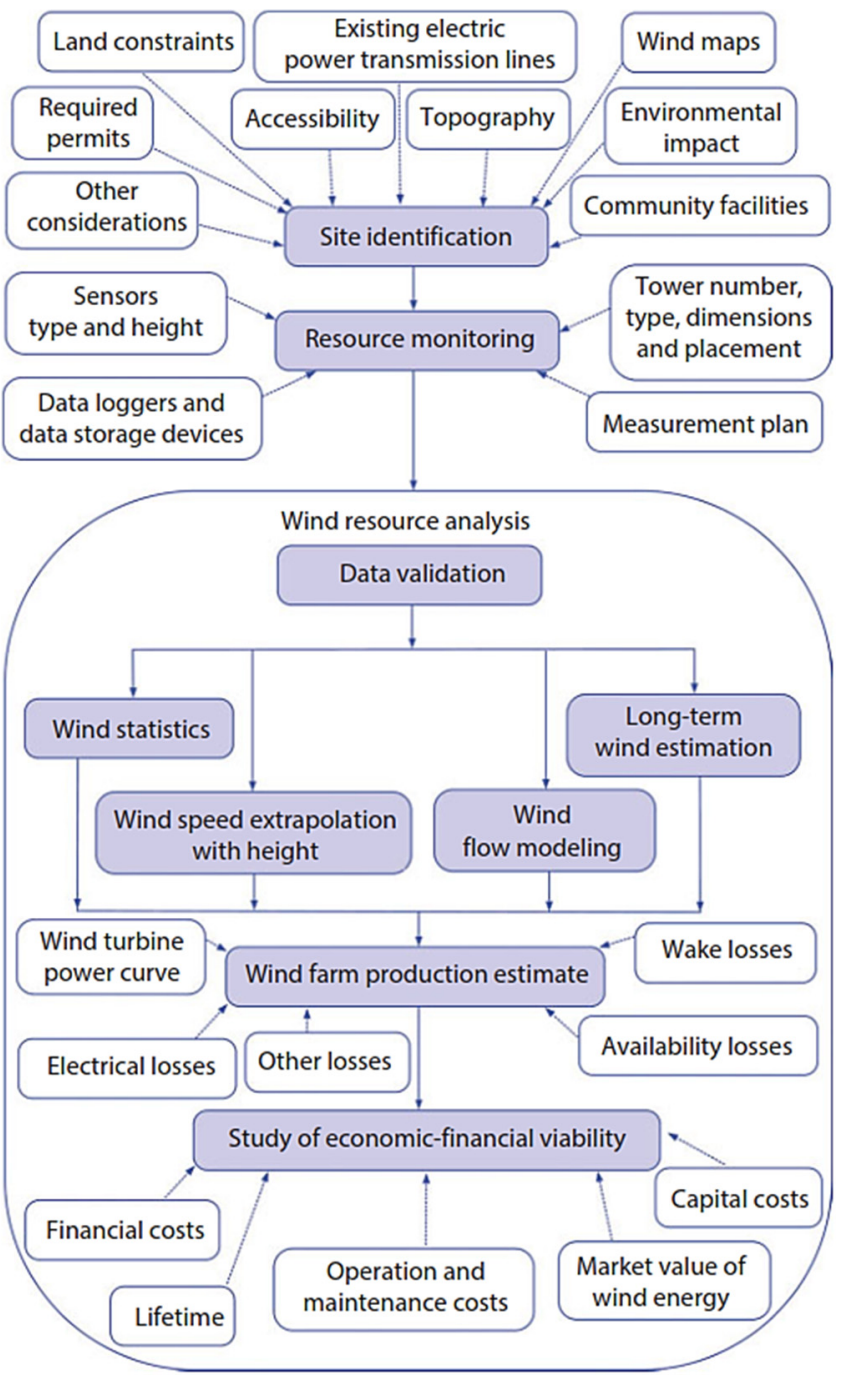

Fig. 3. Overall process of wind resource assessment [14].
- The use of hybrid wind-diesel energy systems to power the desalination technologies. Wind-powered desalination systems are classified as in Figure 7 [14].

\subsection{RO desalination system}

In principle, the RO technology is a membrane-based system that applies hydraulic pressure pushing the water through a semi-permeable membrane. It has been globally used with $65 \%$ of the installed desalination plants. Figure 8 represents the installed technologies and their installed percentages [20].

Several advantages to the use of RO systems [21].

- RO can provide a wide range of production capacities, from small stand-alone installations, delivering less than $1 \mathrm{~m}^{3}$ /day to large-scale plants producing over $500000 \mathrm{~m}^{3} /$ day;

- RO can handle a wide range of feed water salinity including, brackish water and seawater;

- RO plants can provide continuous and reliable operation without shuttingdown for extended periods;

- RO plants operate at low specific energy consumption (SEC) ranging from 2 to $4 \mathrm{kWh} / \mathrm{m}^{3}$.

\subsection{Wind-RO desalination system}

Replacing the traditional Reverse Osmoses desalination plants with a hybrid approach inrenewable energy sources (wind, solar, wave etc.), will reduce the impact of conventional fossil fuel electric power resources and the associated effects on the environment. Wind - desalination system coupled with an RO technology, has a broad acceptance and is limited by [22]:

- Operability over a large power envelope;

- Robustness to feedwater variation; 


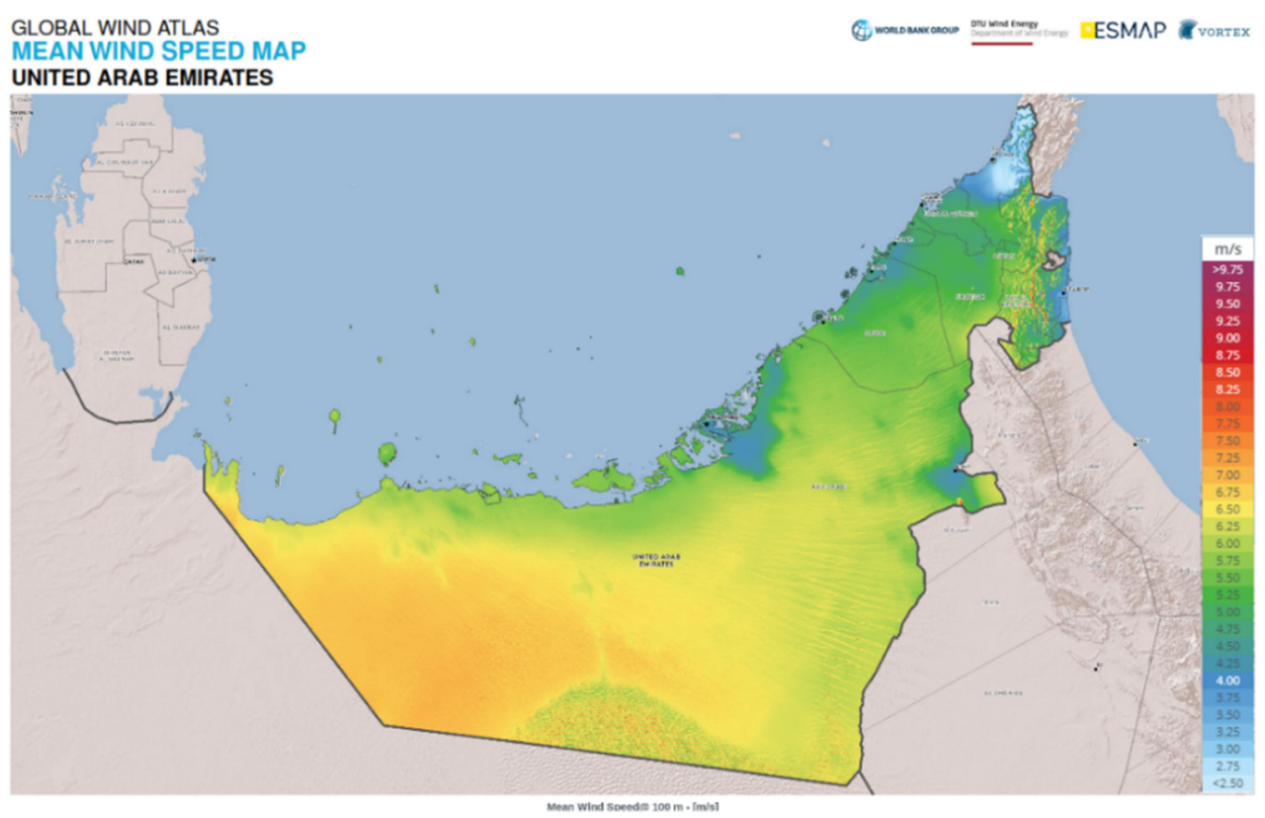

Fig. 4. UAE Wind speed map at $100 \mathrm{~m}$ height [16].
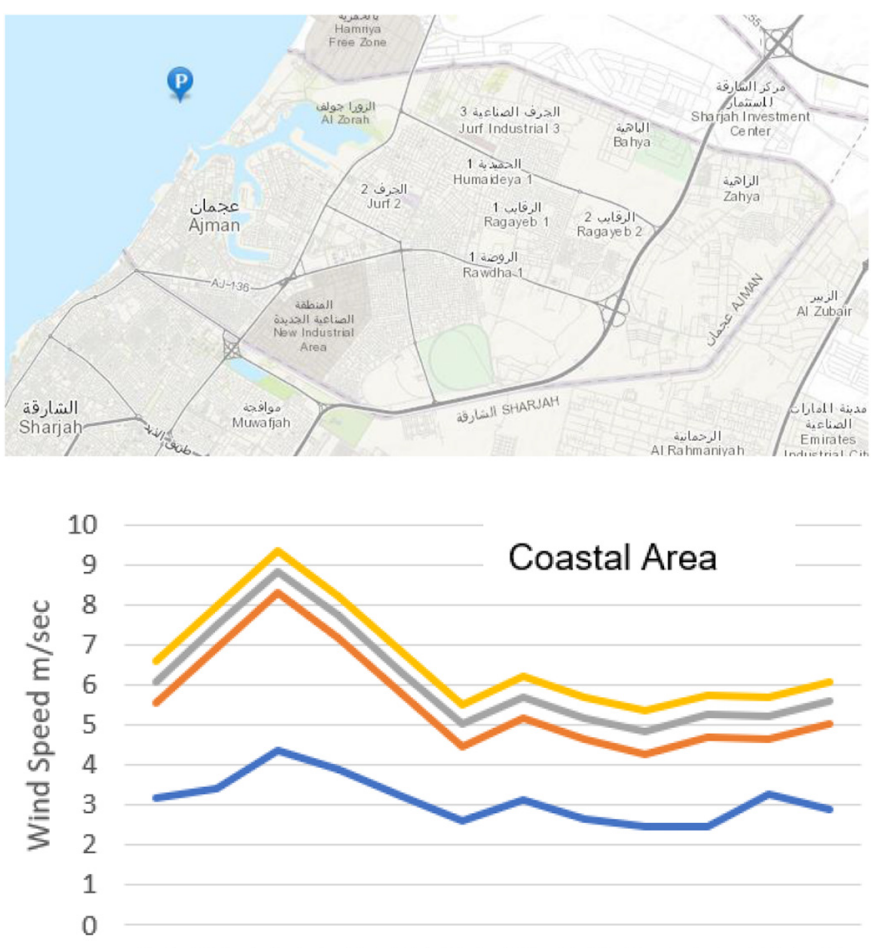

JAN FEB MAR APR MAY JUN JUL AUG SEP OCT NOV DEC

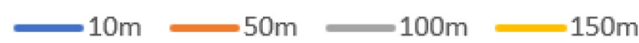

Fig. 5. Coastal area monthly mean wind speed at different heights in Ajman - UAE 2019 [15].

- Management of multiple, often conflicting, requirements;

- In-situ monitoring of membrane degradation and compensation via operations andchemicals;

- Reduction in the cost of water for commercialisation.
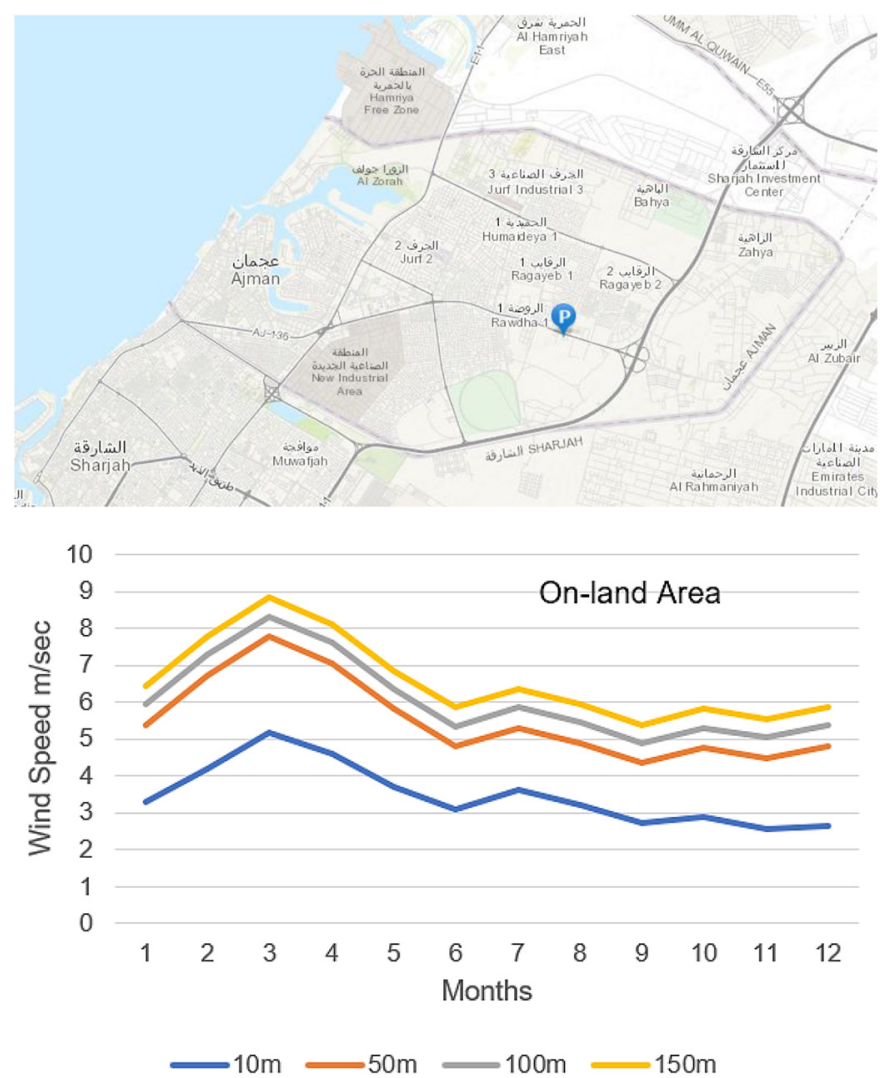

Fig. 6. On-land areas monthly mean wind speed at different heights in Ajman - UAE 2019 [15].

As seen in Figure 9, it has been proved that as the electrical power needed for the RO plant constitutes $44 \%$ of the water cost [23], this power can be generated from renewable energy and wind could have a significant possibility for utilisation $[21,24]$. 


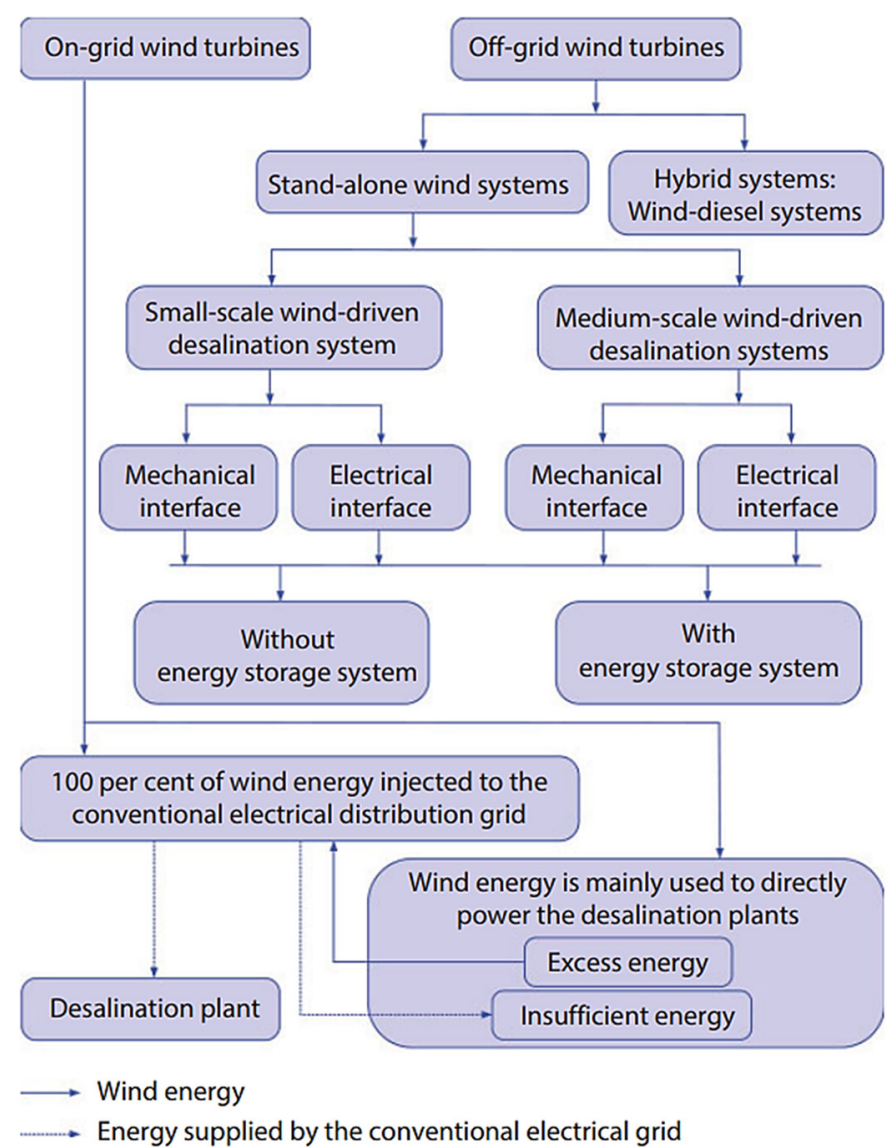

Fig. 7. Classification of wind-driven desalination systems [14].

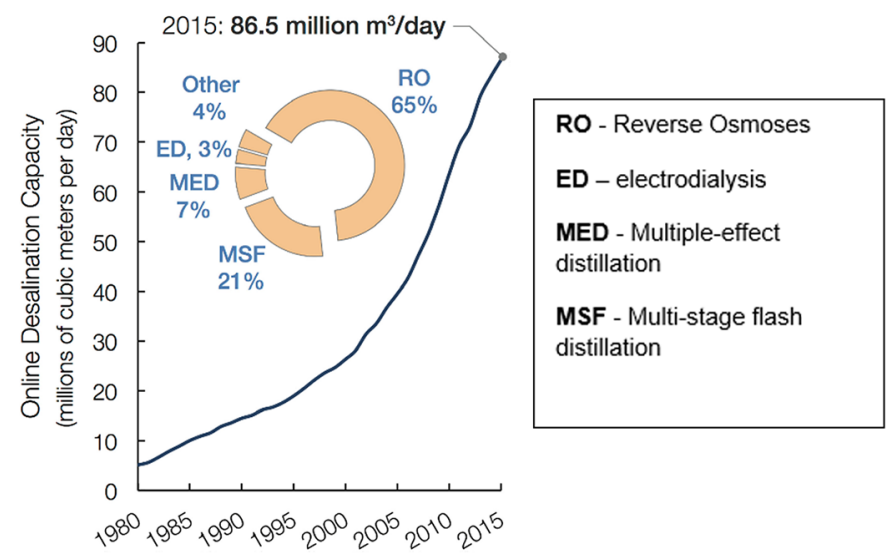

Fig. 8. Worldwide collective desalination unit capacity and methods of desalinationfor the period 1980-2015 [20].

A wind energy conversion system's power output contains the rotor, transmission gearbox, and output load. The turbine starts running with useful power at its cut-in wind speed reaching limited power output at the rating wind speed, and must shut down when the wind speed comes its furling value that might cause damage to the rotor blades, see Figure 10. The interrelation between the available wind speed and the wind turbine's power outputis modelled to calculate the power output related to the

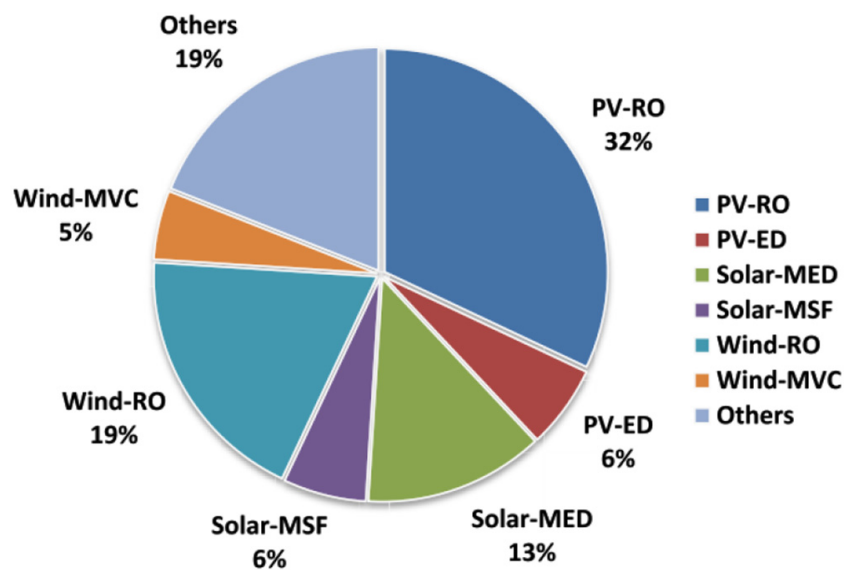

Fig. 9. Distribution of renewable energy powered desalination technology $[21,24]$.

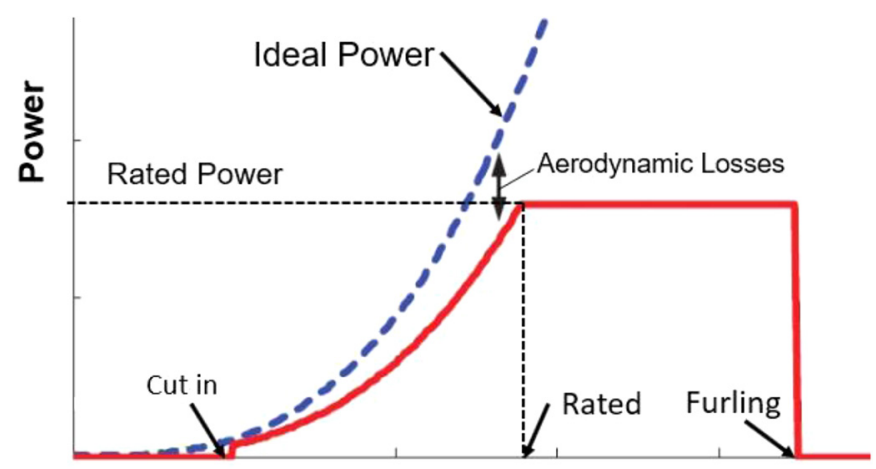

Wind Speed

Fig. 10. Power curve for a wind energy conversion system.

probability density function of Weibull distribution [25]. The coupling interface between wind energy and desalination unit is met at the place/subsystem where the power generated by wind energy is promoted to the desalination plant.

Reverse Osmosis is a pressure-driven process that separatestwo solutions with different concentrations across a semi-permeablemembrane. It consists of four components; membranemodules, high-pressure pumps, power plants, and energy recoverydevices as needed [26]. RO requires about $3-10 \mathrm{kWh}$ of electric energy per $\mathrm{m}^{3}$ of freshwater produced from seawater [27]. Eventually, production cost could be much lower in windy regions and on a more extensive implementation scale (Fig. 11) [28]. Therefore, it is safe to say that independent windpowered desalination systems will have a bright future in the coming years.

\section{Suitable pilot projects: practical examples}

\subsection{Self-contained desalination plant}

These systems are fast small-sized wind turbine that converts the kinetic energy extracted from the wind into electrical energy, and the resulting electricity drives a designed desalination plant according to the power output. 


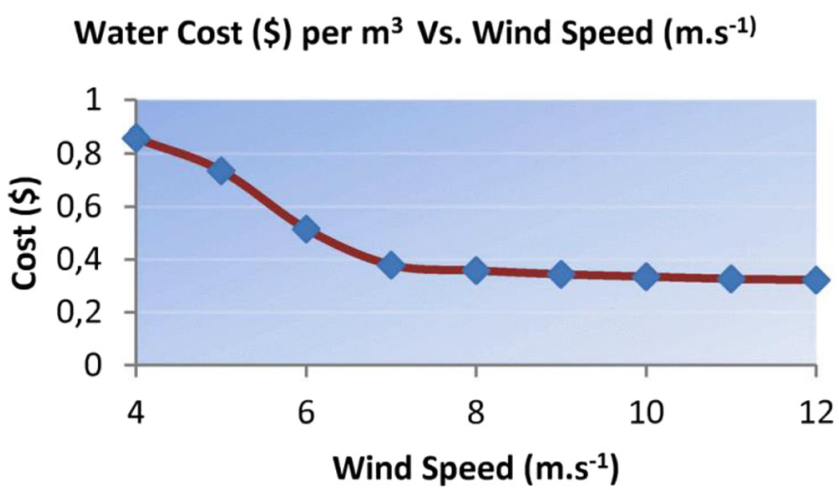

Fig. 11. Water production cost per wind speed [28].

Another choice is a system that directly connects the kinetic energy extracted from the wind with the desalination plant. Figure 12 shows an example $6 \mathrm{~kW}$ wind turbine on Süderoog island (Germany), which was used to power a desalination plant with three RO modules and a maximum production capacity of $0.375 \mathrm{~m}^{3} / \mathrm{h}$ [29].

\subsection{Electrical interface in the coupling between wind energy system and desalination unit}

The middle-sized stand-alone wind-driven desalination systems implemented systems integrating wind turbines with variable-speed rotors directly coupled (without gearbox) to synchronous-type generators with multiple pairs of poles connected to the stand-alone grid via power electronic converters. Enercon's desalination department developed a desalination system designed to be powered explicitly by wind energy. Enercon's desalination system can contain various RO modular units, Figure 13 [14]. This system can be adjusted continuously with RO units to produce between 7.5 and $180 \mathrm{~m}^{3} /$ day, depending on the wind speed availability.

\section{Street lighting system}

The wind potential in Ajman supports a wide range of applications, as shown from wind data in Figures 5 and 6 . Therefore, it is an opportunity that the authority should convert the streets' lighting with new systems powered by renewable energy. This will contribute to the city's sustainable development practices and sustain several advantages, such as:

- Reducing the power transmission loss experienced from the conventional lighting system;

- Supporting the electric grid by reducing the generation load;

- Reducing the CO2 emission and the associated environmental impact;

- Street lights are independent of the utility grid;

- Require much less maintenance compared to conventional street lights;

- They are of accidents are minimised;

- Energy costs can be saved.
Wind turbines placed middle way or on top of the street lighting post can generate enough power backed with a battery system can be the perfect system. These lighting systems are either driven by a horizontal axis or vertical axis wind turbines. These turbines can capture the "wind" produced by cars' passage and convert it into electricity. The turbine is used to power two LED lamps that guarantee the illumination of the roadway. The system is, therefore, will illuminate the road for $24 \mathrm{~h}$ [30,31]. Figure 14 is for the vertical axis example, and Figure 15 represents a hybrid system (Solar-Wind) using a horizontal axis wind turbine [32].

\section{Building integrated wind technology for lighting purposes}

The principle of considering self-powered buildings by implementing renewable energy is discussed on different occasions, energy-saving technology controlled by artificial intelligence and smart technology. It is highly recommended that the Emirate of Ajman implement the latest renewable energy systems integrated or augmented to the existing or newly built building, emphasising the use of smart technology to control and support the whole process. Main advantages were concluded in [33]:

- Meet targets of green building designers;

- Promote sustainability in the built environment;

- Minimum transmission/distribution losses;

- Accessing greater wind velocities at higher altitudes $40 \%$ increase;

- Replace the existing buildings with self-sufficient energy buildings;

- Satisfy up to $20 \%$ of the building's energy needs;

- Present an ecological power generation in the future of the sustainable building;

- Can play a crucial role in unexpected situations delivering lacking energy;

- New wind turbines are developed quietly, with no vibration, and high-power output;

- Provide visible evidence to a building owner's commitment to the environment and increase the building performance's energy rating;

- Wind will complement solar PV integrated systems to sustain the energy supply for a sustainable building and reach more than $40 \%$ of the building demand.

Each building in Ajman, especially the newly built ones and the Governmental buildings, can achieve $10 \%$ of its demand, covering the building lighting. It has been shown that wind technologies are most efficient when augmented to buildings, specifically the high buildings, as the wind speeds are higher at higher heights, Figures 5 and 6 . The systematic framework introduced by [34], Figure 16, can be used as guidance and a model for implementing the wind technologies in buildings [33,34]. Possible methods are shown in Figure 17.

Examples of building-mounted wind turbine with a vertical axis rotor type and building-mounted wind turbine with a horizontal axis rotor type are shown in Figures 18 and $19[34,35]$. 


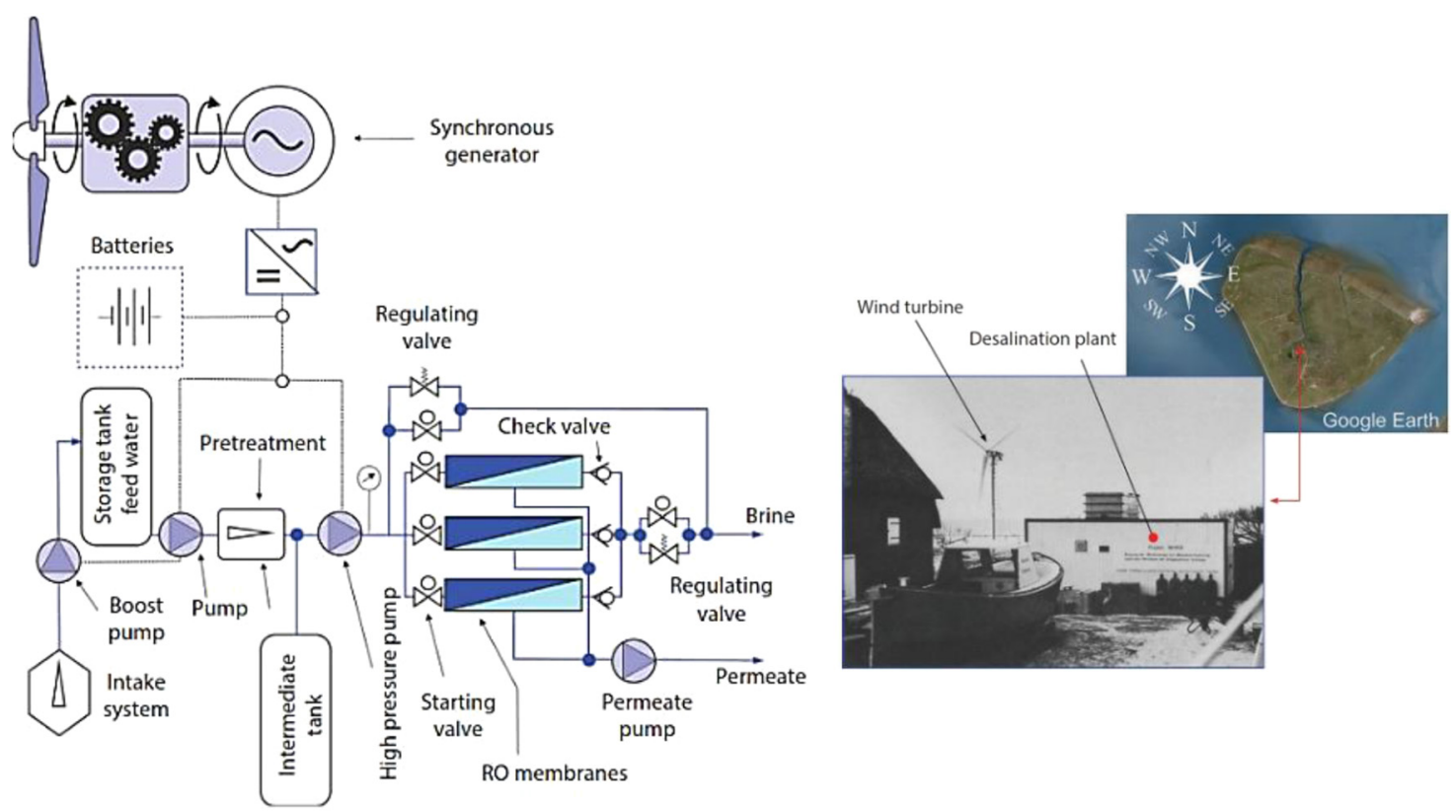

Fig. 12. Wind energy converter and self-contained desalination plant installed by [29].

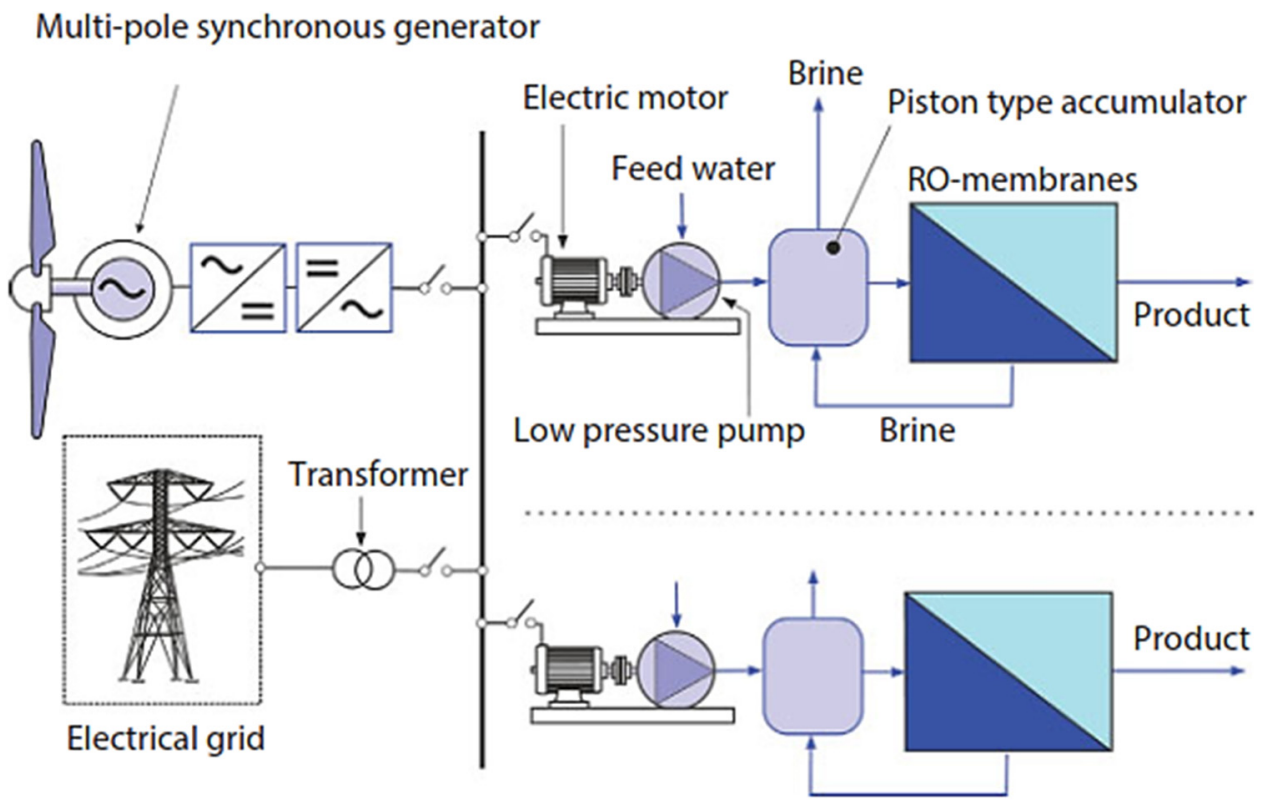

Fig. 13. Basic schematic representation of the medium-scale wind-driven desalination system developed by Enercon [14].

Therefore, using renewable energy on buildings will become more profitable nowadays because of applying advanced technology and using wind energy technology to create comfort with low energy consumption. In this situation, the systems' performance that takes energy from renewable sources and converts it into useful energy is growing [36].

To approach the sustainable environmental buildings, it is essential to set a sustainable strategy for the city and introduce a green building code guideline. However, the lack of building regulations is apparent. It needs to be revised in favourites of greenery and saving lands to allow housing developers to build on the land plot's edge without a setback from three sides of the land [37].

\section{Conclusions}

Wind energy utilisation in the Emirate of Ajman - UAE was reviewed in this article considering the available wind data for two areas, offshore Monthly mean wind and the onshore regions at different heights. It is concluded that 

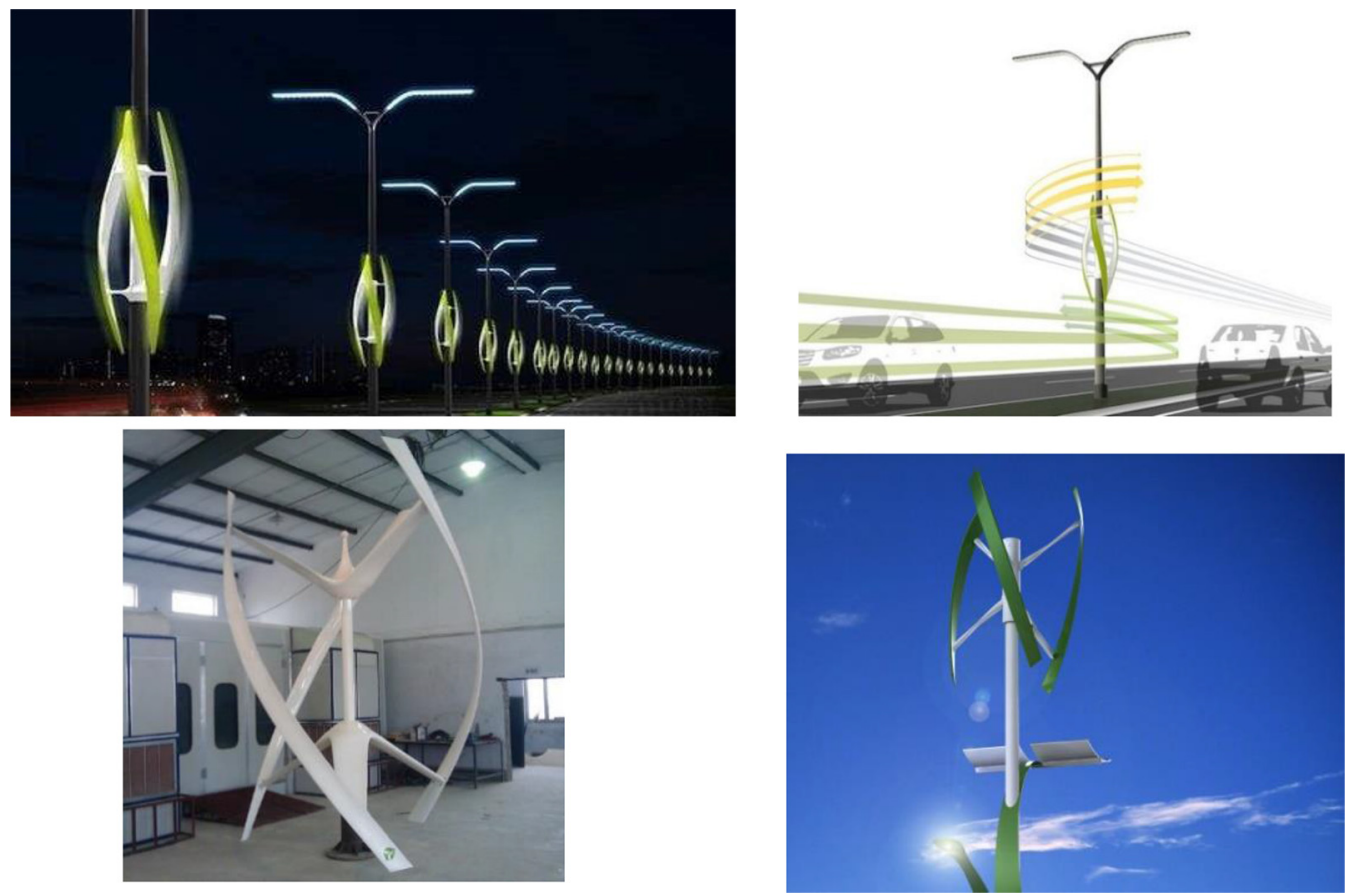

Fig. 14. Vertical axis wind - street lighting system [30,31].
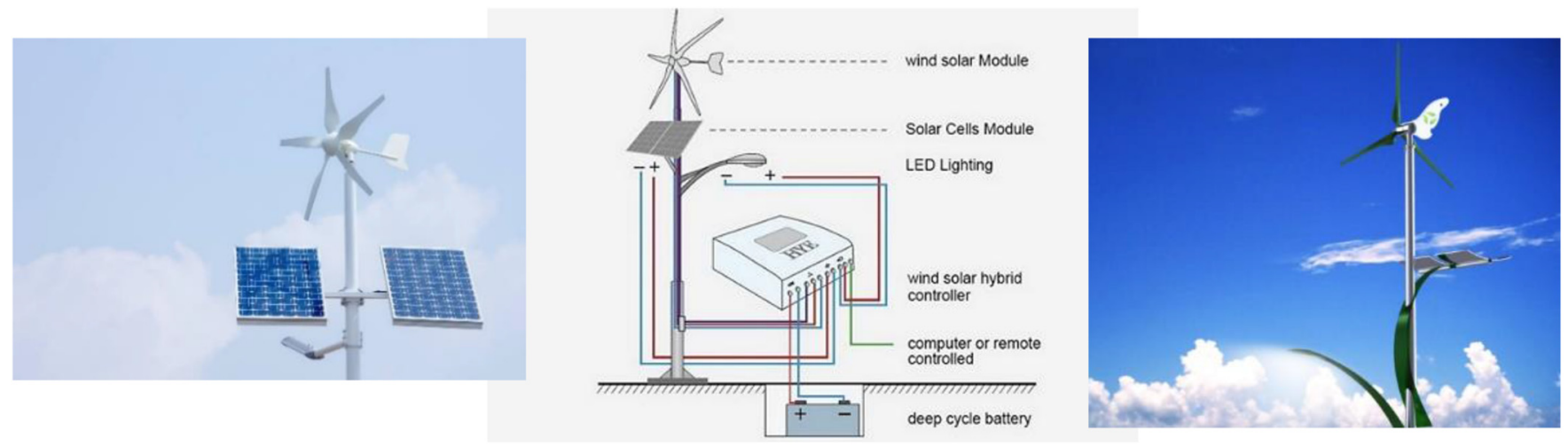

- $\quad$ Photovoltaic (PV) module- monocrystalline/polycrystalline

- HY Series small wind turbine-400W/600W/1500W/3000W (12V/24/48/96V)

- $\quad$ Light source - ultra bright LED light 20/30/40/60/80/90/120W

- Controller - 5/10/15A wind solar hybrid controller, automatic light controller, automatic operation, multi work mode, over charge protection, high wind protection etc.

- $\quad$ Energy Storage - sealed maintenance free AGM gel deep cycled battery

- Battery Box - water proof design battery box

- Light Pole $-6 / 8 / 10 / 12 / 16 \mathrm{~m}$ light pole with $30 / 50 \mathrm{~m} / \mathrm{s}$ wind resistance

Fig. 15. Hybrid street lighting system [32].

theseareas are suitable for wind energy utilisation. Mean wind speed values between $6.5 \mathrm{~m} / \mathrm{s}$ and $7.5 \mathrm{~m}$ at the buildings' height level, encouraging different types of utilisation. The paper reviews possible technologies such as seawater desalination, street lighting and buildings integration for lighting purposes. Desalination techniques were reviewed. The most applicable system is the Reverse Osmosis (RO) system driven by wind turbines supported by battery banks or solar panels to sustain its operation. The paper presented a comprehensive description of wind 


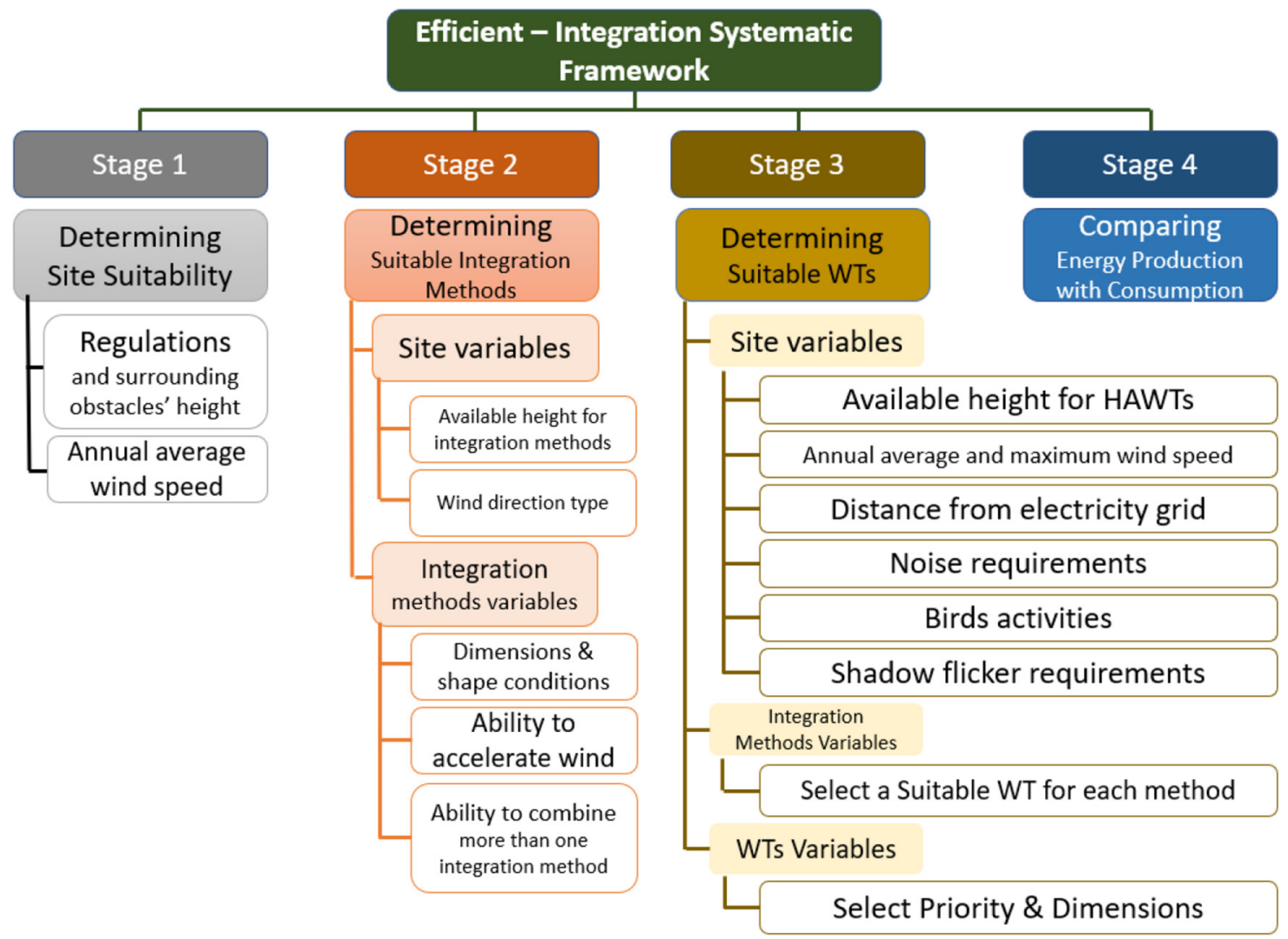

Fig. 16. Systematic framework for the efficient integration of WTs into buildings [34].

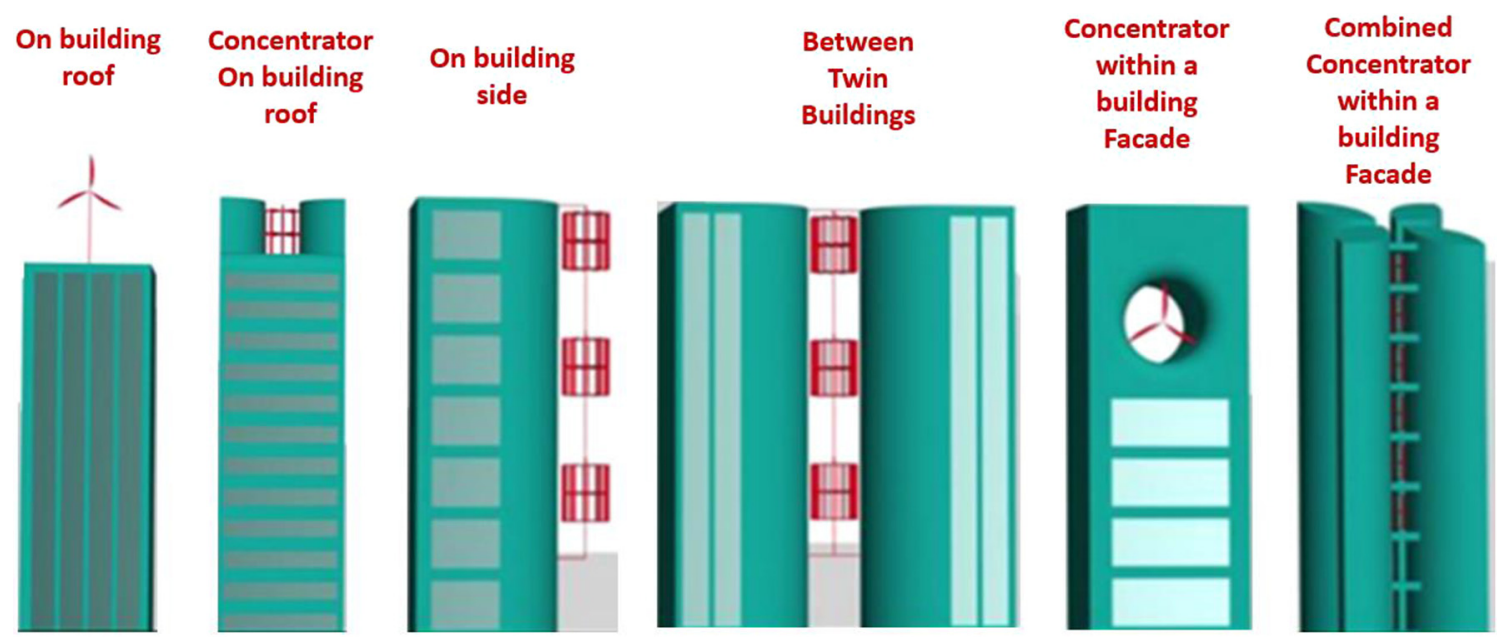

Fig. 17. Main methods of wind turbines Integrated into Buildings [34].

desalination techniques applicable to this Emirate and provided practical examples. The article has also introduced the street Lighting as another application for utilising wind energy, specifically at motorways as there is plenty of wind created by vehicles' motion. Suitable systems for the Emirate of Ajman that consist of hybrid resource (Solar \& Wind) street lighting were discussed and practical examples of designs were presented. Buildings' integrated wind technology has also been considered as another area for wind energy utilisation and verified for its feasibility to be implemented at this Emirate moving the building construction sector to sustainable structural 

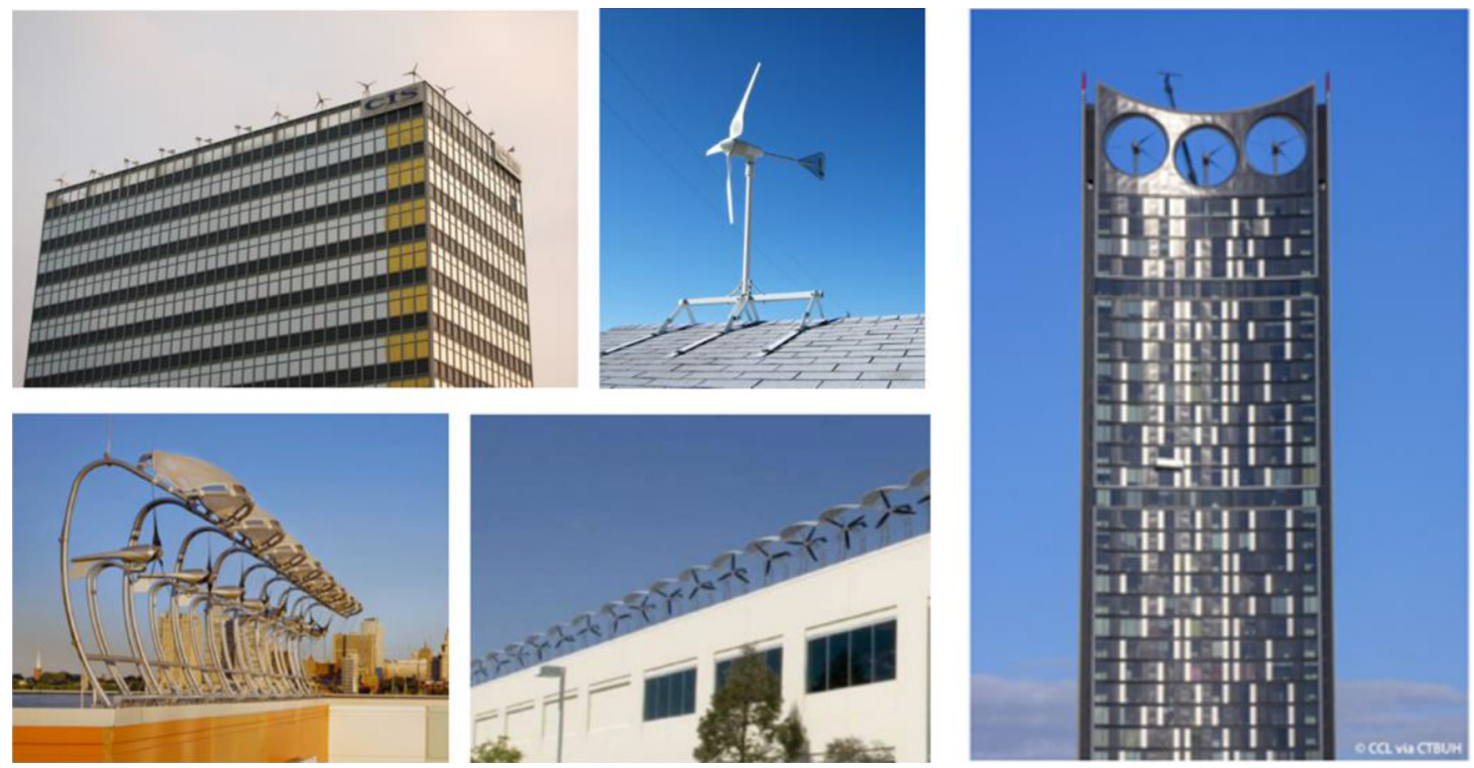

Fig. 18. building-mounted wind turbine with a vertical axis rotor type [34,35].
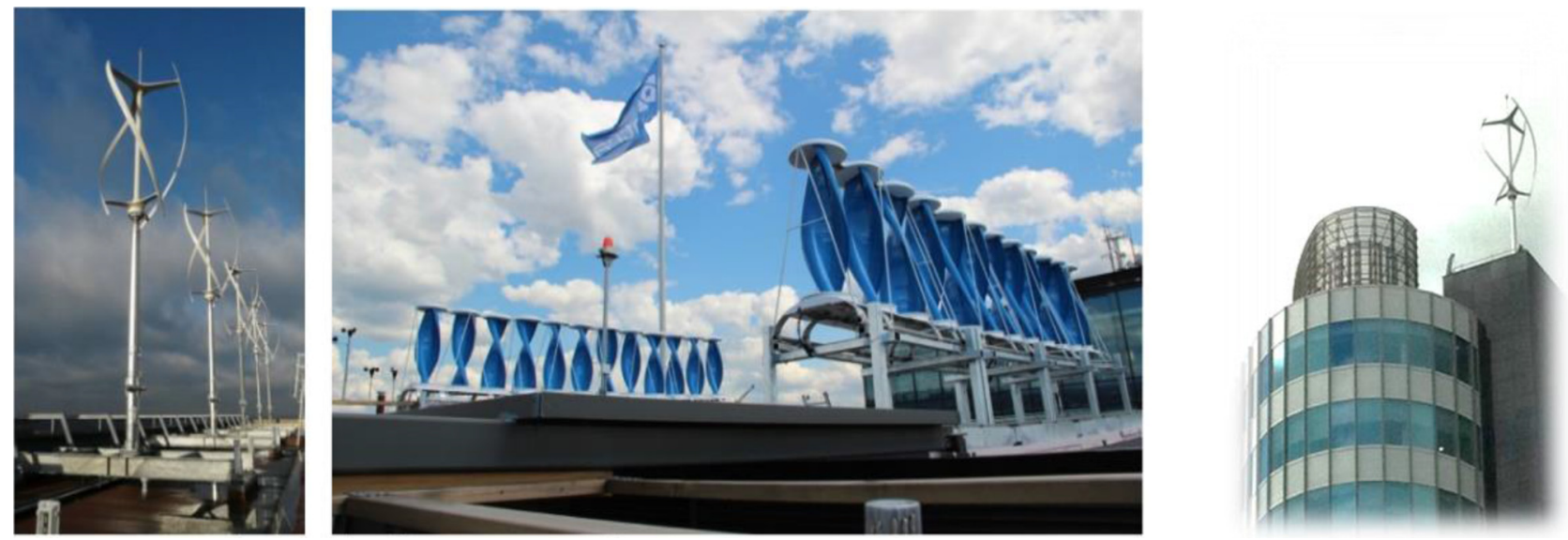

Fig. 19. Building-mounted wind turbine with a horizontal axis rotor type [34].

development. Moreover, it can be concluded that the available wind energy density at this Emirate can contribute to $20 \%$ of the Emirate's total electricity demand. It will have the advantage to have the Emirate enhance its contribution and performance towards sustainable development goals initiated by the UAE Government.

\section{References}

1. A.S. Darwish, Can Bahrain generate $20 \%$ of their electricity from wind? Third Symposium on CLIMATE CHANGE, Green Cities, Sustainable Buildings, and RENEWABLE ENERGY Including Waste Management - Kingdom of Bahrain, 27th and 28th January 2019. Kingdom University \& World Renewable Energy Network, Manama, 2019

2. U.ae., The UAE's response to climate change, 2021. Retrieved from UAE Government Portal: https://u.ae/en/ information-and-services/environment-and-energy/climatechange/theuaesresponsetoclimatechange
3. Climate action tracker, UAE Country Summary, 2021. Retrieved from Climate Action Tracker: https://climateac tiontracker.org/countries/uae/

4. A.S. Darwish, Renewable energy utilization - aspects and innovations: sustainable, green, and smart buildings in the Emirate of Ajman, in: Ajman 4th International Environment Conference 2016, 2016. Ajman - UAE: Science Target. Retrieved from http://aiec.ae/ar/assets/lectures/day2/07AIC2018-Prof-A-S-Darwish.pdf

5. A.M. Eltamaly, Design and implementation of wind energy system in Saudi Arabia, Renew. Energy 60, 42-52 (2013)

6. IRENA, IEA-ETSAP, Water desalination using renewable energy: insights for policy makers, 2013

7. H.-J. Lee, F. Sarfert, H. Strathmann, S.-H. Moon, Designing of an electrodialysis desalination plant, Desalination 142, 267-86 (2002)

8. M.A. Eltawil, Z. Zhengming, L. Yuan, A review of renewable energy technologies integrated with desalination systems, Renew. Sustain. Energy Rev. 13, 2245-2262 (2009)

9. E. Mathioulakis, V. Belessiotis, E. Delyannis, Desalination by using alternative energy: review and state-of-the-art, Desalination 203, 346-365 (2007) 
10. L. García-Rodríguez, V. Romero-Ternero, C. Gómez-Camacho, Economic analysis of wind- powered desalination, Desalination 137, 259-265 (2001)

11. I. Nuez Pestana, F.J.G. Latorre, C.A. Espinoza, A.G. Gotor, Optimisation of RO desalination systems powered by renewable energies, Part I: wind energy, Desalination 160, 293-299 (2004)

12. M. Forstmeier, F. Mannerheim, F. D'Amato, M. Shah, Y. Liu, M. Baldea, A. Stella, Feasibility study on wind-powered desalination, Desalination 203, 463-470 (2007)

13. N. Saleous, S. Issa, J. Al Mazrouei, GIS-based wind farm site selection model offshore Abu Dhabi Emirate, UAE, The International Archives of the Photogrammetry, Remote Sensing and Spatial Information Sciences XLI-B8, 2016, pp. 437-441

14. J. Gonzalez, P. Cabera, J. Carta, Wind energy powered desalination systems, in: J. Kucera (Ed.), Desalination Water From Water, Wiley, Beverly, 2019, pp. 567-646

15. L. NASA, POWER data access viewer, 2020. https://power. larc.nasa.gov/data-access-viewer/ (accessed February 7, 2021)

16. DTU, United Arab Emirates Wind Atlas, 2019. https:// globalwindatlas.info (accessed January 12, 2021)

17. A.S.K. Darwish, A.A.M. Sayigh, Wind energy potential in Iraq, Solar \& Wind Technology 5, 215-222 (1988)

18. E.K. Akpinar, S. Akpinar, An assessment on seasonal analysis of wind energy characteristics and wind turbine characteristics, Energy Conversion and Management 46, 1848-1867 (2005)

19. A. Ucar, F. Balo, Evaluation of wind energy potential and electricity generation at six locations in Turkey, Applied Energy 86, 1864-1872 (2009)

20. M.A. Abdelkareem, M. El Haj Assad, E.T. Sayed, B. Soudan, Recent progress in the use of renewable energy sources to power water desalination plants, Desalination 435, 97-113 (2018)

21. M. Mito, X. Ma, H. Albuflasa, P. Davies, Reverse osmosis (RO) membrane desalination driven by wind and solar photovoltaic (PV) energy: state of the art and challenges for large-scale implementation, Renew. Sustain. Energy Rev. 112, 669-685 (2019)

22. NREL, Integrated wind energy/desalination system, National Renewable Energy Laboratory, New York, 2005

23. National Research Council, Review of the desalination and water purification technology roadmap, National Academy of Sciences, 2004
24. N. Ghaffour, J. Bundschuh, H. Mahmoudi, M.F.A. Goosen, Renewable energy-driven desalination technologies: a comprehensive review on challenges and potential applications of integrated systems, Desalination 356, 94-114 (2015)

25. P. Feron, The use of windpower in autonomous reverse osmosis seawater desalination, Wind Engineering 9, 180-199 (1985)

26. C. Fritzmann, J. Löwenberg, T. Wintgens, T. Melin, Stateof-the-art-of reverse osmosis desalination, Desalination 216 , 1-76 (2007)

27. D. Colombo, M. de Gerloni, M. Reali, An energy-efficient submarine desalination plant, Desalination 122, 171-176 (1999)

28. Y. Dahioui, K. Loudiyi, Wind powered water desalination, in: International Renewable and Sustainable Energy Conference (IRSEC), IEEE, 13 June 2013, Ouarzazate, Morocco

29. G. Petersen, S. Fries, J. Mohn, A. Müller, Wind and solarpowered reverse osmosis desalination units - description of two demonstration projects, Desalination 31, 501-509 (1979)

30. A. Iannicelli, Turbine light: "wind-powered" streetlights for motorways, 2019. https://www.thepatent.news/2019/12/ 19/turbine-light-wind/ (accessed January 11, 2021)

31. B. Meinhold, Sleek solar and wind powered hybrid street lamps, 2009. https://inhabitat.com/hybrid-wind-solarstreet-lamps/ (accessed January 11, 2021)

32. Solarstreetlighting. Solar \& wind - hybrid lighting, 2021. http://www.solarstreetlighting.co.uk/products/solar-windhybrid-lighting/ (accessed January 11, 2021)

33. A.S. Darwish, Green buildings to approach sustainable buildings by integrating wind and solar systems with smart technologies, in: Sayigh A. (Ed.) Green Buildings and Renewable Energy. Innovative Renewable Energy, Springer, Cham 2020

34. A.A. ELMokadem, N.A. Megahed, D.S. Noaman, Systematic framework for the efficient integration of wind technologies into buildings, Frontiers of Architectural Research 5, 1-14 (2016)

35. M. Haase, E. Löfström, Building augmented wind turbines BAWT: integrated solutions and technologies of small wind turbines, SINTEF akademisk forlag, 2015, SINTEF Fag (34)

36. G. Ivan, R. Crutescu, C. Ivan, N. Ivan, Using renewable energy to create comfort in the first Romanian passive house suited for offices, Renewable Energy and Environmental Sustainability 1, 11 (2016)

37. F. Al Kubaisy, Greenery buildings significance of courtyard houses design in the Arab world, Renewable Energy and Environmental Sustainability 5, 5 (2020)

Cite this article as: Abdul Salam K. Darwish, Wind energy utilisation for water desalination, street and buildings lighting a case study for The Emirate of Ajman - UAE, Renew. Energy Environ. Sustain. 6, 10 (2021) 